\title{
Philosophical Thinking on the Revolution of the Relationship Between Human and Machine in the Era of Artificial Intelligence
}

\author{
Jiahao Zhu ${ }^{1, *}$ Guiqing $\mathrm{Li}^{1}$ and HuijunXia ${ }^{1}$ \\ ${ }^{1}$ School of Management, Chengdu University of Information Technology, Chengdu, Sichuan 610103, China \\ *Corresponding author. Email: zhujiahao96@foxmail.com
}

\begin{abstract}
With the improvement of the intelligence level of artificial intelligence, the distinction between human and machine has become more and more blurred, which has caused a great impact on the traditional humanmachine relationship. This paper considers the relationship between human and machine in the era of artificial intelligence from a philosophical point of view, and concludes that the relationship between human and machine in the era of artificial intelligence is still a subject-object relationship, a division of labor and cooperation relationship, and the relationship between man and machine is affected by social attributes, which provides certain insights for establishing a new type of human-machine relationship. After studying the specific content of the impact of AI on human society, it is concluded that the way of thinking, production and labor, and lifestyle of people will be changed in the era of artificial intelligence. Finally, it points out the challenges of traditional job substitution, increased social inequality, and ethical destruction in the development of AI, and it also gives some strategies to promote the development and application of AI, to promote the development of service industry and create new working forms, and to design AI that in line with human ethics, which provides effective social governance measures about AI for all social parties.

Keywords: artificial intelligence; philosophical thinking; social impact; coping strategies
\end{abstract}

\section{INTRODUCTION}

Since the State Council issued "Made in China 2025" in 2015, it has emphasized the need to seize the historical period when the new round of scientific and technological revolution and industrial reform meet with China's accelerated transformation of economic development mode, in order to build China into a manufacturing power leading the development of the world's manufacturing industry. China has successively issued the "Internet + AI Threeyear Action Implementation Plan", the "New Generation Artificial Intelligence Development Plan", the "Three-year Action Plan for Promoting the Development of the New Generation Artificial Intelligence Industry (2018-2020)", "Artificial Intelligence Standardization White Paper (2018 Edition)" and other policies. With the attention and promotion of top-level design, the level of research and development of artificial intelligence in China has ranked among the top in the world, and its application scope has also penetrated various fields such as agriculture, industry, finance, communications, education, medical treatment and transportation, and it plays a positive role in promoting the optimization and upgrading of these fields.

In the near future, artificial intelligence is likely to become an important factor driving social structural, overall and revolutionary changes, pushing human society into the era of artificial intelligence. But on the other hand, With the rapid improvement of the intelligence level of AI, the distinction between human and machine has become more and more blurred, which has caused a great impact on the traditional human-machine relationship. Here, this paper considers the relationship between human and machine in the era of artificial intelligence from a philosophical point of view, and then studies the specific content of the impact of artificial intelligence on human society from three perspectives: way of thinking, production and labor, and lifestyle. Finally, the challenges in the development of artificial intelligence are pointed out, and the corresponding countermeasures are given so that all parties in the society can take more effective measures in social governance.

\section{THE RELATIONSHIP BETWEEN HUMAN AND MACHINE IN THE ERA OF ARTIFICIAL INTELLIGENCE}

\subsection{The Distinction Between Human and Machine Is Getting Blurred}

Karl Marx once pointed out: "As soon as human begin to produce their means of subsistence, that is, when they take the step determined by their physical organization, human begin to distinguish themselves from animals." What 
makes a man is not only that he has subjective initiative, but also that he can transform nature through practice to make it conform to his living environment. With the continuous breakthroughs of artificial intelligence, machines are becoming more and more intelligent. If most of human activities can be undertaken by intelligent machines, humans will lose their essence -- labor. As Kevin Kelly said, "Artificial objects behave more and more like living bodies; life becomes more and more engineered."

If there are essential differences between human and machine as different external entity, then the combination of intelligent technology and biotechnology such as braincomputer interfaces, will make the distinction between human and machine more and more blurred, and the boundary between human and non-human will no longer exist. This brings us to the famous paradox -- The Ship of Theseus, as the biological parts of a person body are gradually replaced by machine parts, then when all the biological parts are replaced, will the person still be the original person? If he isn't the original person, when did he cease to be the original person?

\subsection{The Relationship Between Human and Machine Is Still Subject-object Relationship}

The ethical risks, social inequality, unemployment and other issues brought by the development of artificial intelligence have further aggravated the public's negative impression of artificial intelligence, and people even have the illusion that machines will rule mankind. Jeffrey Hawkins pointed out: "People have such concerns because they combine intelligence (the algorithm of the neocortex) with the emotional factors of the ancient brain (such as fear, paranoia, and desire). " Intelligent machines will not have the same emotions as human, nor will they seek social recognition and sexual satisfaction. They will not jump out of the scope of the system settings, only know to persevere in doing their own things. That is to say, the realization of intelligence does not mean that it is simultaneously endowed with value and normative components such as intention, motivation, and emotion.[1] Intelligent machines that are objects and have no subjective initiative cannot rule mankind. Most people are ruled by a few elites who master or control intelligent machines. The relationship between man and machine has always been a manmachine-man relationship. The relationship has always been a subject-object relationship. Even if intelligent technology and biotechnology are combined, human biological components are gradually replaced by machine components. These machine components are only to enhance human physical or mental capability. The ultimate goal is to better serve human. The relationship between human and machine is still a subject-object relationship.

\subsection{The Relationship Between Human and Machine Is a Division of Labor and Cooperation Relationship}

In the 1980s, Hans Moravec, Rodney Brooks and Marvin Minsky proposed the Moravec Paradox: the unique highlevel intelligence to human requires very little computing power, but unconscious skills and intuition require great computing power. Simply put, it is relatively easy to make a computer play chess like an adult, but it is quite difficult to make a computer have the senses and actions like a oneyear-old child. Artificial intelligence is the product of human rational thinking. What it can do is also based on rational thinking, and its capture of human perceptual thinking is extremely limited. As a man who combines sensibility and rationality, he naturally has one more perceptual dimension than artificial intelligence, which is more able to reflect human emotions and intuition. In Marxist philosophy, different things have different contradictions, which constitute the special essence of this thing which is different from other things. In terms of human-machine cooperation, the essence of human is to be able to coordinate perception and rationality, and make behavioral decisions according to the principle of satisfaction; the essence of machine is to use purely rational calculations and output results according to the principle of optimization. Therefore, human and machine should have a clear division of labor, use their respective advantages to complement each other, and promote the improvement of work efficiency.

\subsection{The Relationship Between Human and Machine Is Affected by Social Attributes}

In real human society, machine (technology) has never been merely a production tool, but has been deeply branded with production relations and social system.[2] The machine (technology) of capitalist society is deeply branded with capitalist production relations and social system. The capitalist mode of production has enabled mankind to create more wealth in more than two hundred years than any previous period combined, but it has also brought about a series of alienation. Although machine has become a new source of wealth, due to some invisible force, machine has become the root of poverty. Although machine can reduce human labor and improve labor efficiency, it has caused hunger and fatigue of workers. Affected by the capitalist production relations, producers and means of production began to separate. Workers are no longer the main parties in the production process, but stand beside the production process. The relationship between workers and machines is not harmonious. In the communist society envisioned by Marx and Engels, the foundations of all old relations of production and communication will be overthrown, and they will be controlled by the united individuals. Artificial intelligence and other technologies are no longer tools for the minority to exploit the majority, but are for the benefit of everyone, and achieve the free and 
comprehensive development of individuals and all mankind.

\section{IMPORTANT CHANGES IN THE ERA OF ARTIFICIAL INTELLIGENCE}

As a social activity of human beings, science and technology will inevitably affect other social activities. Every progress in science and technology is manifested in promoting the transformation of economic development mode, changing social management methods, improving human cognitive ability, and improving cultural communication and education methods. As Engels said at the tomb of Marx: "In Marx's view, science and technology is a driving and revolutionary force in history." The fourth scientific and technological revolution that is centered on artificial intelligence is currently breaking out. Artificial intelligence has been widely used in human society, and its application will inevitably cause profound changes in human production and life.

\subsection{Changes of Human Thinking in the Era of Artificial Intelligence}

\subsubsection{Understanding the instrumental nature of artificial intelligence, people's attitude towards artificial intelligence has changed from rejection to acceptance}

At first, because of concerns about the "singularity" theory put forward by Ray Kurzweil and fear of the destruction of employment prospects by the high efficiency and low cost of artificial intelligence, people's attitude towards artificial intelligence related things was resistant. Only some insiders and scholars are advocating the advantages of artificial intelligence. After that, people gradually understood the truth that "similar to the imitation and enhancement of human physical strength by machines, artificial intelligence is only the imitation and enhancement of human intelligence"[3], and more and more artificial intelligence products enter people's lives, bringing many changes to people's lives and improving people's living standards. Finally, many people have realized the transition from adapting to artificial intelligence products to relying on artificial intelligence products. Just like electronic payment, the total amount of mobile payment in China had increased year by year from 2010 to 2019, and the total amount of mobile payment exceeded 10 trillion yuan each year from 2016 to 2019. In 2019, the total amount of mobile payment in China was 2161.5 billion yuan.[4] Few people are willing to go back to the days of using cash. Nowadays, people often choose electronic payment as a means of settlement when they carry out economic activities.

\subsubsection{It has reshaped the relationship between man and nature in the era of artificial intelligence}

Ethics refers to the relationships between man and man, and between man and nature, and the rules for handling these relationships. With the development of human society, people's understanding of ethics is constantly changing. According to A. Leopold, the "community" applicable to "ethics" is gradually expanding: from the beginning it only applies to masters (slave owners and other free people), not to slaves, later became a "human ethics" that only applies to human, not to other species. Today, the boundaries of the "community" applicable to "ethics" should be further expanded. "land" includes "soil, water, plants, and animals", "land ethics" declares their right to continue to exist, and at least in some respects, they have the right to continue to exist in a natural state.[5] Now that artificial intelligence is gradually integrated into our lives, covering all aspects of our lives, the boundaries of the "community" applicable to "ethics" will also continue to expand. It includes not only human, animals, plants, microorganisms and other organic organisms, but also artificial intelligence products with inorganic structures are also included, forming a new type of ethical relationship.

\subsubsection{Transformation of thinking from "capital economy" to "smart economy"}

The goal of the first two industrial revolutions was to onesidedly pursue material life. Entrepreneurs used all means for profit and benefit, causing a series of problems such as resource exhaustion, ecological degradation and air pollution. In the era of artificial intelligence, knowledge is more powerful than material, and intelligence is more powerful than knowledge. Different from the material economy driven by energy in the industrial age, workers are employed by capital and earn money with their own intelligence and physical strength, but they cannot make a lot of money. The era of artificial intelligence is an intelligent economy driven by intelligence. There is a general surplus of capital in the market, but intellectual capital is relatively scarce. A large amount of capital is chasing intellectual capital in order to increase value. In recent years, the scale of China's smart economy market has increased substantially, the proportion of smart economy in China's GDP has increased year by year, and it is now close to one-third, and the proportion of developed countries such as the United States, Germany, and Britain is more than $50 \%$ of GDP.[6] The core role of intellectual capital has become increasingly prominent, the status of mental workers has improved, and the market's large demand for intellectual capital has made people pay more and more attention to education. The shortage of school district housing and the opening of various training courses signify the change of people's way of thinking. 


\subsection{Changes in Human Production and Labor in the Era of Artificial Intelligence}

\subsubsection{Having more advanced equipment}

Science and technology have promoted the development of industry. The material wealth created by machines in less than a century of the industrial revolution is more than that created by mankind in thousands of years. In the wool textile industry before the adoption of the steam engine, the annual output in 1788 was 75,000 pieces, but after the steam engine was adopted, the annual output increased to 490,000 pieces in 1817.[7] In the era of artificial intelligence, artificial intelligence has a more revolutionary impact on productivity and industrial structure, making the production process more automated and intelligent, effectively promoting the upgrading of traditional industries, driving the rapid development of "unmanned economy", and bringing the prosperity of various related industrial chains. For example, in the manufacturing sector, the daily production capacity of the mask machine developed by the AVIC Manufacturing Technology Institute can reach 140,000 masks.[8] Volkswagen's factory in Slovakia currently only takes about 50 seconds to produce each car.[9] Robots with artificial intelligence technology can quickly grasp and be familiar with important data such as production processes and product design parameters, and automatically select and match according to production requirements, thereby achieving high-efficiency production.

\subsubsection{Establishing man-machine partnership}

The difference between artificial intelligence equipment and human at work is obvious. Through machine learning and deep learning, artificial intelligence equipment can master the information that human needs to spend a lot of time and energy in a short period, and artificial intelligence equipment can always remain rational when working for a long time, and will not be distracted. Human beings can work with artificial intelligence equipment to help themselves save a lot of time for other tasks, thereby improving work efficiency. Conversely, the high efficiency of artificial intelligence equipment can only be highlighted within a fixed scope of work. It is powerless for tasks that require flexibility, and due to the lack of empathy for human emotions, it is difficult to complete interpersonal communication activities well. Artificial intelligence equipment needs to work under the guidance of human at this time, so as to give full play to its advantages. In the era of artificial intelligence, human needs machines to assist their work, and machines need human to guide them. The efficiency of human-machine cooperation exceeds that of any party. Taking AI medical treatment as an example, Harvard pathologists used AI technology to identify breast cancer cells with an accuracy rate of $99.5 \%$, which exceeded 96\% when human pathologists work alone and 92\% when AI works alone.[10] Simply saying "machines are not as good as human" or "human is not as good as machines" is inappropriate. Human and machines should complement each other according to their respective advantages and capabilities, and establish a cooperative system to help people break through the limits of various natural forces of mankind, so that people can become stronger and more powerful in practice.

\subsubsection{Changes in traditional labor relations}

With the rise of network platforms, more and more people have become online contract workers. This new form of labor meets the characteristics of enterprises' pursuit of low cost and convenience, and laborers' pursuit of freedom and timely return, but its boundary has the ambiguous characteristic. The unclear characteristic pushed the traditional dualism of "labor relations and non-labor relations" to an end.[11] On the one hand, the main function of the platform is to provide technical support and create a virtual market that connects users and gig workers freely. The platform does not own the ownership of the gig workers' labor data, and the gig workers have nothing to prove their identity as employees. On the other hand, gig workers are like employees of platform companies. They must abide by the various rules and regulations related to the platform, and the final salary share is also related to the scores completed by users through the platform. Their relationship with the platform is to a certain extent in line with the legal "employee" requirements between the two have a "control" relationship.[12] The new type of labor relationship formed by gig workers and Internet platforms is an intermediate form of traditional labor relations and has the characteristics of both "self-employed" and "otheremployed" labor relations.[13] This undoubtedly has a huge impact on traditional labor relations, and there may be more diversified labor relations in the future, which will profoundly change people's perception of labor relations.

\subsection{Changes in Human Lifestyles in the Era of Artificial Intelligence}

\subsubsection{Impact on learning style}

Artificial intelligence, big data and cloud computing have achieved MOOCs and micro-classes. We can learn anytime and anywhere through smart devices, which greatly increases our learning time and enriches our learning methods. We can use some software based on artificial intelligence technology on the Internet to help us learn, such as machine translation, text recognition and speech recognition. Thanks to the tremendous progress of various technologies in the era of artificial intelligence, we can find our personalized education resources on the Internet, and some colleges and universities will also publish open courses online for free, which is also of great practical 
significance for solving the problem of educational imbalance.

\subsubsection{Impact on working mode}

Affected by the COVID-19 epidemic, remote office software has been widely used by enterprises and individual users. As of June 2020, the number of remote office users in China has reached 199 million, accounting for $21.2 \%$ of the total Internet users.[14] In the era of artificial intelligence, people can break the barriers between time and space, and our working mode will be greatly changed. People don't have to go to a fixed place to work, they can do office activities at home or in the car. Through effective use of resources and efficient allocation of supply and demand, people can achieve the freedom of working hours, which may generate a large number of freelancers.

\subsubsection{Impact on travel mode}

In the era of artificial intelligence, people are inseparable from services such as online car-hailing and car-sharing. These services are fast and convenient, have a short waiting time, and have lower fees. They fully utilize idle social resources and improve transportation efficiency and reduce energy consumption. Intelligent traffic management system based on artificial intelligence, information communication, sensing and control technologies can greatly improve road usage efficiency. Public data shows that intelligent traffic system can reduce traffic congestion by about $60 \%$ and increase existing road capacity by $2-3$ times. ${ }^{[6]}$ At the same time, the success of self-driving cars will bring a series of positive effects. For example, it can reduce traffic accidents caused by human errors and fatigue, and it also brings hope to people with mobility impairments.

\subsubsection{Impact on home life}

A few years ago, home service robots were far from the lives of ordinary people, but now, more and more consumers are using home service robot products. In 2018, the scale of China's smart home market reached 6.532 billion US dollars, ranking second in the world after the United States. ${ }^{[6]}$ For example, the sweeping robot "Roomba" can efficiently clean the ground, and the intelligent robot "Xiaodu" can meet the various needs of people at home. These robots reduce people's housework to a certain extent, so that people can spend their time on more meaningful things.

\section{CHALLENGES IN THE ERA OF ARTIFICIAL INTELLIGENCE}

In 2017, the "Notice of the State Council on Issuing a New Generation of Artificial Intelligence Development Plan" emphasized: "Artificial intelligence is a disruptive technology with a wide range of influences. It may bring about issues such as changing the employment structure, impacting laws and social ethics, violating personal privacy, and challenging international relations norms, which will have profound impacts on government management, economic security, social stability and even global governance." In the era of artificial intelligence, we must attach great importance to the security risks that may be brought about by the development of science and technology, minimize the negative impacts of risks, and ensure that the scientific and technological achievements of the era of artificial intelligence are shared by all people.

\subsection{Replacement of Traditional Jobs}

Every industrial revolution is about the transfer and adjustment of labor, just like the replacement of labor, this new cycle is no exception. According to Accenture, one of the biggest tasks of AI is to redesign work. Some of the operational jobs will be replaced by AI, and humans will concentrate on perceptive jobs. Traditional technical jobs will also be replaced by innovative jobs. ${ }^{[10]}$ Compared with human, AI has high-speed computing power, super environmental adaptability and stable working ability without emotional fluctuations. Relying on these advantages, employers will be more inclined to use AI to replace human to complete some simple and repetitive work. Labor with cumbersome calculations or a poor working environment will also be completed by AI. Daron Acemoglu concluded through modeling analysis that for every AI robot used, the local wage level will drop by $0.73 \%$, which is equivalent to the loss of 6.2 jobs.[15] The World Economic Forum's survey prediction is also a similar conclusion. With the popularization of artificial intelligence, about 5.1 million jobs will disappear, and these jobs are mainly labor-intensive jobs.[16]

\subsection{Exacerbating Social Inequality}

Power in traditional society is based on political power or military force, and power in modern society may come from capital. In the era of artificial intelligence, an invisible wealth and power foundation that is more flexible than gold, currency, and land is taking shape. This foundation is information or data. Information or data that can produce huge economic benefits will become the most powerful resource in society or the power that represents the historical trend of society, and will naturally become the reliable foundation of power.[17] Those few intellectual elites who undertake the research and development of artificial intelligence technology may have extraordinary influence and voice. They constitute a new social class in the era of artificial intelligence and become an important part of social power. As Yuval Harari pointed out: "As algorithms crowd humans out of the job market, wealth and power may be concentrated in the hands of very few elites 
with powerful algorithms, causing unprecedented social and political inequality." The analogy to the era of the Internet, a small number of people (as of June 2020, the number of non-netizens in China is 436 million $^{[14]}$ ) are reduced to information poor and information refugees due to reasons such as unable to go online, no access to go online, and unwilling to go online. It puts forward higher requirements for knowledge system, information resources and grasp of opportunities in the era of artificial intelligence. These information poor and information refugees may be abandoned by society, leading to further intensification of social polarization.

\subsection{Challenges to Ethics}

The new wave of artificial intelligence is driven by data and algorithms. Artificial intelligence is inseparable from the feeding of massive data and the support of advanced algorithms. In life, whether we are voluntary, forced, intentional or unintentional, our personal information, activity information, and life information will be collected by artificial intelligence, which is likely to trigger a serious privacy crisis. The traditional view of privacy holds that individuals have the right to control and delete their own information. But when people's information becomes electronic, the traditional right to privacy is obviously challenged. We no longer have the right to control and delete our information.[18] In order to protect the security of personal information, how to ensure that AI cannot read personal information without permission and enable individuals to have the right to access information against $\mathrm{AI}$ is an urgent matter to be solved. In addition, many pictures of black are labeled as chimps by artificial intelligence, Microsoft chatbot Tay made racist remarks, a Tesla electric car in self-driving mode caused a car accident and caused the death of the car owner. This series of practical problems have brought severe challenges to ethics.

\section{COUNTERMEASURES IN THE ERA OF ARTIFICIAL INTELLIGENCE}

\subsection{Actively Promoting the Development and Application of Artificial Intelligence}

Because of its advantages of high efficiency and low cost, artificial intelligence will replace a large number of traditional jobs, causing short-term structural unemployment in the labor market and widening the income gap. But at the same time, it will also fill the positions that people are unwilling to work in or incompetent for, create a new job market, and change the employment structure of the labor force.[19] Accenture's economic model predicts that if companies' investment in AI reaches the world's leading level, they will increase their income by $38 \%$ and employment by $10 \%$ in the next five years. ${ }^{[10]}$ It can be seen that the application of AI has not only not reduced the employment rate, but increased the employment rate of various industries. We should actively promote the $R \& D$ and application of artificial intelligence. The first is to strengthen research in basic fields including frontier basic theories, underlying technologies, key common technologies, and basic software and hardware; the second is to develop brain science, cognitive science, psychology and other disciplines related to artificial intelligence technology, and encourage cross-disciplinary research; the third is to learn from the US government-university-industry R\&D ecosystem, establish a platform integrating production, education and research, promote open sharing of data resources, and accelerate the application of artificial intelligence in all walks of life.

\subsection{Promoting the Development of the Service Industry and Creating New Forms of Work}

Different from the regularity and repetitiveness of the manufacturing industry, the service industry is an industry full of sociality and flexibility, and it is difficult to be replaced by artificial intelligence. Actively promoting the development of the service industry can not only meet people's growing consumption demand, but also create a large number of jobs. On the other hand, there may be two important changes in the nature of employment in the era of artificial intelligence: the first is that there will be much less time to work, and people may no longer need to spend a whole block of time for work; the second is that work may change more frequently, and people may need to constantly change their jobs.[20] This requires a more flexible form of work that can make full use of people's fragmented time to work. It is particularly important to guide and promote the development of the sharing economy and gig economy.

\subsection{Designing AI That Conforms to Human Ethics}

In the era of artificial intelligence, moral constraints should be strengthened so that artificial intelligence can develop within a framework that conforms to human morality. The US "National Artificial Intelligence Research and Development Strategic Plan: 2019" proposes that the ethical, legal, and social issues of artificial intelligence should be solved by improving the fairness, transparency and accountability of the AI system, and designing an AI architecture that conforms to human ethics. At the same time, the AI system must also have a strong performance to prevent external attacks and deal with internal problems to ensure the security of users' personal information. In addition, in order to ensure the safe, reliable, and controllable development of artificial intelligence, the construction of the legal system should also attach great 
importance to data and information security issues, privacy issues, various types of discrimination and prejudice issues, ethical issues that may arise in the development of artificial intelligence. Based on the issues, it's necessary to formulate practical laws and regulations to escort the benign development of artificial intelligence.

\section{CONCLUSION}

The third wave of artificial intelligence has arrived, the impact of this wave is far greater than the previous two. Artificial intelligence has shown a powerful enabling role in various fields, pushing human society into the era of artificial intelligence. In daily life, various applications of artificial intelligence have been generally accepted and expected by people, and have had a great impact on the way of thinking, production and labor, and lifestyle of people. For the negative impact of artificial intelligence technology, we should be prepared to deal with it, and adapt to the opportunities and challenges brought by this wave. We should realize that artificial intelligence is only a tool to help human complete practical activities. Whether it is good or bad depends on our use and application methods. We should actively use the advantages of artificial intelligence technology to promote the development and transformation of human society, and comprehensively improve people's quality of life.

\section{ACKNOWLEDGMENT}

We thank the support from the National Social Science Foundation Annual Project of China (19GBL123).

\section{REFERENCES}

[1]Hengwei Li, Haosheng Wang, "Reasons for the threat of artificial intelligence: the technological singularity theory and its refutation”, Zhejiang Academic Journal, 2019, No.2, pp.53-62. DOI: 10.16235/j.cnki.33-1005/c.2019.02.007

[2]Jinfang Chang, “A man-machine-man relationship in the age of artificial intelligence--some thoughts based upon Marxist philosophy”, Southeast Academic Research, 2019, No.2, pp.75-82. DOI: 10.13658/j.cnki.sar.2019.02.009

[3]Feng Xiao, "The multiple implications of the view on machine in Das Kapital for understanding artificial intelligence”, Studies on Marxism, 2019, No.6, pp.1826.

[4]iiMedia, "Mobile payment industry data analysis: China's mobile payment products totaled 2161.5 billion yuan in 2019", https://www.iimedia.cn/c1061/68685.html, 2020-2-7.
[5]A. Leopold, “A sand county almanac”, Wenhui Hou Trans. Changchun: Jilin People’s Press, 1997, pp.193213.

[6]China Development Research Foundation, Baidu, "New infrastructure, new opportunities: white paper on China's smart economy development (essence edition)”, Beijing, 2019

[7]Ying Tong, “A brief history of world modern science and technology development”, Shanghai: Shanghai People's Publishing House, 1990.

[8]National Business Daily, “Chinese aviation people use the F-20 technology to create a fully automatic mask machine, which can produce 100 masks per minute", http://finance.sina.com.cn/wm/2020-03-12/dociimxxstf8529177.shtml, 2020-3-12.

[9]Xzlrobot, "Volkswagen industry 4.0 Factory: 30,000 robots build a car in 50 seconds", http://robot.ofweek.com/2018-06/ART-8321202-850030238497.html, 2018-6-7.

[10]HRSalon, “Accenture executive Tracy talks about artificial intelligence reshaping the workforce of the future", https://baijiahao.baidu.com/s?id=159887287893179058 $3 \& w f r=s p i d e r \& f o r=p c, 2018-4-27$.

[11]W David Allen, "Social networks and selfemployment”, Journal of Socio-Economics, 2000, No.5, pp.487-501. DOI: 10.1016/S1053-5357(00)00086-X

[12]Lao M, "Workers in the gig economy: the case for extending the antitrust labor exemption to them”, SSRN Electronic Journal, 2017, vol.51, pp.1543-1587. DOI: $10.2139 /$ ssrn.3015477

[13]Si Lian, Wencheng Mou, “The latest developments of foreign scholars' research on internet contractors and its enlightenment to China”, China Youth Study, 2020, No.7, pp.112-118. DOI: 10.19633/j.cnki.112579/d.2020.0109

[14]China Internet Network Information Center, "The 46th China statistical report on Internet development”, Beijing, 2020.

[15]Daron Acemoglu, P Restrepo, "Robots and jobs: evidence from US labor markets”, NBER Working Paper, 2017, vol.23285, pp.1-62. DOI: 10.3386/w23285

[16]World Economic Forum, "Centre for the new economy and society, the future of jobs report 2018”, 
https://www.weforum.org/docs/WEF_Future_of_Jobs_2 018.pdf, 2018-09-17.

[17]Juanli Ye, Qin Xu, “De-centralization and centralization: paradox of power in the age of artificial intelligence”, Journal of Shanghai University(Social Sciences Edition), 2019, No.6, pp.1-12. DOI: 10.3969/j.issn1007-6522.2019.06.001

[18]Weiwei Zhang, "The influence of artificial intelligence on human and social development”,
Guangzhou: South China University of Technology, 2018.

[19]Zhou Deng, Yana Huang, “A study of the influence of artificial intelligence development on employment”, Study \& Exploration, 2019, No.7, pp.99-106.

[20]Yongwei Chen, Zhaorui Zeng, "Economic consequences of "the second machine revolution": growth, employment and distribution", Study \& Exploration, 2019, No.2, pp.101-113. 